\title{
A new animal model for relapsing polychondritis, induced by cartilage matrix protein (matrilin-1)
}

\author{
Ann-Sofie Hansson, ${ }^{1}$ Dick Heinegård, ${ }^{2}$ and Rikard Holmdahl ${ }^{1}$ \\ ${ }^{1}$ Section for Medical Inflammation Research, Department of Cell and Molecular Biology, Lund University, \\ 22362 Lund, Sweden \\ ${ }^{2}$ Section for Connective Tissue Biology, Department of Cell and Molecular Biology, Lund University, \\ 22100 Lund, Sweden \\ Address correspondence to: Ann-Sofie Hansson, Section for Medical Inflammation Research, Lund University, \\ Sölvegatan 19, 22362 Lund, Sweden. Phone: 46-46-2223349; Fax: 46-46-2223110; E-mail: Ann-Sofie.Hansson@inflam.lu.se.
}

Received for publication November 6, 1998, and accepted in revised form July 19, 1999.

Relapsing polychondritis (RP) differs from rheumatoid arthritis (RA) in that primarily cartilage outside diarthrodial joints is affected. The disease usually involves trachea, nose, and outer ears. To investigate whether the tissue distribution of RP may be explained by a specific immune response, we immunized rats with cartilage matrix protein (matrilin-1), a protein predominantly expressed in tracheal cartilage. After 2-3 weeks, some rats developed a severe inspiratory stridor. They had swollen noses and/or epistaxis, but showed neither joint nor outer ear affection. The inflammatory lesions involved chronic active erosions of cartilage. Female rats were more susceptible than males. The disease susceptibility was controlled by both MHC genes ( $f, 1, d$, and a haplotypes are high responders, and $\mathrm{u}, \mathrm{n}$, and $\mathrm{c}$ are resistant) and non-MHC genes (the LEW strain is susceptible; the DA strain is resistant). However, all strains mounted a pronounced IgG response to cartilage matrix protein. The initiation and effector phase of the laryngotracheal involvement causing the clinical symptoms were shown to depend on $\alpha \beta$ T cells. Taken together, these results represent a novel model for RP: matrilin1 -induced RP. Our findings also suggest that different cartilage proteins are involved in pathogenic models of RP and RA.

J. Clin. Invest. 104:589-598 (1999).

\section{Introduction}

The role of cartilage proteins in rheumatoid inflammation has been investigated for many years, with a major focus on collagens. It is documented in several reports $(1-5)$ that at least in a portion of the patients with rheumatoid arthritis (RA) and relapsing polychondritis (RP), an immune response against cartilage collagen II can be detected. However, studies of responses against noncollagenous components of cartilage are limited (6-8). If an autoimmune response to cartilage proteins is involved in RA and RP, the different patterns of affected tissues can best be explained if the respective targets are proteins with specific tissue distributions. Whereas RA preferentially affects diarthrodial joints, $\mathrm{RP}$ is a multisystemic disorder with inflammatory attacks on cartilage in different organs and, preferentially, in the perichondrial layer of the cartilage (9-11). The inflammatory infiltrates consist of neutrophils, lymphocytes, macrophages, and plasma cells. In early lesions, eosinophils can be observed close to the affected cartilage $(9,12)$. A classical appearance of RP is the "saddle nose," caused by erosive inflammation of the nasal septum. Another typical symptom is an inflamed external ear (89\% involvement) (10). Occasionally, joints are affected as a seronegative nonerosive arthritis (13). The most severe complication of RP is the involvement of the laryngotracheal cartilage, sometimes leading to lethal breathing difficulties (14). Early signs of airway involvement are cough, dysphonia, and tenderness over the thyroid cartilage. As for many of the autoimmune disorders, there is an unknown, and most likely complex, etiology of RP with a polygenic influence on disease susceptibility. Remarkably, however, RP is associated with the same HLA haplotype (DR4) as RA, and has approximately the same relative risk $(11,15)$.

Much of our understanding of the basic mechanisms of autoimmune diseases has been obtained through animal models, such as in the case of collagen-induced arthritis (CIA), wherein the animals are immunized with collagen type II (CII) (16). In recent years, other components of the cartilage have been shown to be involved in arthritis development in animal models. This is the case for another cartilage-specific collagen, collagen type XI (CXI) (17), and also for another major constituent of cartilage, aggrecan (18). More recently, autoimmune arthritis has been induced by a noncollagenous minor component of cartilage, cartilage oligomeric matrix protein (COMP) (19).

Cartilage matrix protein (CMP) is a noncollagenous protein found in the extracellular matrix in cartilage tissue (20) that shows a distribution between cartilages partially different from COMP. It was first reported in 1979, and has since been cloned and sequenced (21-25).

CMP consists of 3 identical disulfide-bonded subunits of approximately $50 \mathrm{kDa}$ assembled into a trimer via a coiled-coil domain in 1 end (26). The protein may have a 

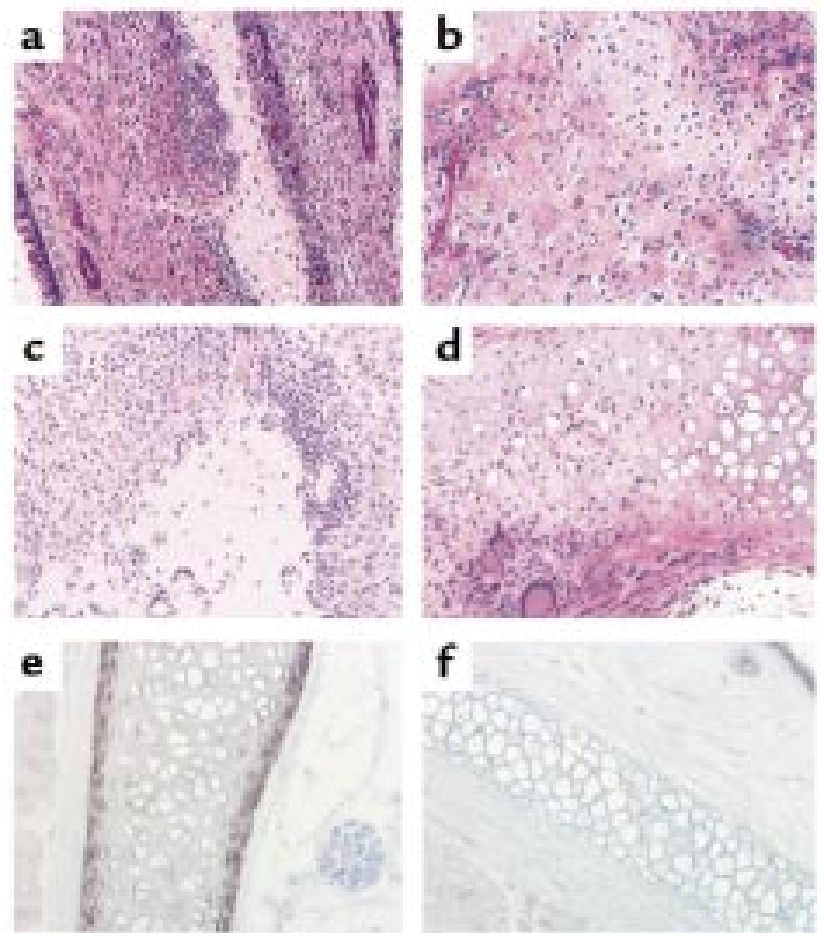

\section{Figure 1}

Sections of nasal and laryngeal cartilage from female LEW.1F rats. (a and b) Nasal septum from rats immunized with CMP. (a) Tissue taken at day 18 after immunization. Erosion of the nasal septal cartilage caused by inflammatory cells is seen. (b) Tissues taken in chronic phase, 120 days after immunization. Shown are irregular tissue and new formation of cartilage, i.e., new irregular cartilage tissue outside the original and normal cartilaginous structures. (c and d) Laryngeal tissue from rats immunized with CMP. (c) Tissue taken day 18 after immunization. A massive invasion of inflammatory cells is seen causing cartilage erosion. (d) Tissues taken in chronic phase, 120 days after immunization. Irregular tissue, new formation of cartilage, and a small area of inflammatory cells are seen. (a-d) Hematoxylin and erythrosin staining. (e and $\mathbf{f}$ ) Staining with CMP-specific polyclonal antibodies. Tissue from a normal female LEW.1F rat showing positive staining in larynx (e) but not in the ear (f). (a-f) Original magnification: $\times 200$.

role in the collagen network, as it may bind CII molecules via 1 or both of its 2 von Willebrand factor-like domains (27). The total amount of CMP increases dramatically with age in tracheal cartilage, where the protein is most abundant, and it has therefore been proposed as a marker of cartilage aging (28-30). In the bovine, it is expressed in considerable amounts in tracheal rings, but also in nasal septum, auricular and xiphisternal cartilage, and the growth plate (30). The same pattern is found in human tissues, with high amounts of CMP in the trachea (31). Notably, it has not been found in normal human or bovine articular cartilage, in contrast to most of the other components of hyaline cartilage. However, a recent report suggested that CMP was synthesized by chondrocytes in cartilage from patients with active RA (32). This may be insignificant, because other data indicate lower levels in synovial fluids from active RA joints than in serum from the same patient (31), indicating that local production is negligible, if present at all.
In recent years, 2 new members of the same family as CMP have been identified - matrilin-2 and matrilin-3 - and it has been proposed to rename CMP matrilin-1 $(33,34)$. These closely related proteins all contain 1 or 2 von Willebrand factor domains with a variable number of repeat EGF-like domains. There are, however, important differences between the expression patterns of the 3 proteins: matrilin- 2 has not been detected in cartilage, whereas matrilin-3 is present in cartilage.

When a cartilage is involved in processes that alter the metabolic activity, intact or fragmented matrix macromolecular constituents are released; these constituents have been detected in body fluids, including serum. Interestingly, increased levels of CMP in the circulation were found in several patients with RA and juvenile arthritis (31), despite its absence from the joint. This indicates involvement of cartilage outside the joint. This approach has been adapted in studies of tissue activity in the trachea in patients suffering from RP. The serum concentration of the protein was found to correlate well with the severity of the airway symptoms, indicating that CMP may be involved in the disease course (35).

To investigate whether CMP is just an indicator of the disease process or may actually play a pathological role in polychondritis, we immunized a series of genetically different rat and mouse strains. In LEW rat strains with the a, l, d, or f MHC haplotype, and in the DBA/1 mouse strain, a disease developed that, to a large extent, resembled human RP. The animals suffered from breathing difficulties caused by an inflammatory attack on the upper airways. Other inflammatory target tissues were the nose and, probably secondarily, the kidneys - thus mimicking disease symptoms in RP.

\section{Methods}

Animals. The rat strains studied originate from Zentralinstitut Fur Versuchstierzucht (Hannover, Germany), and the mouse strains from The Jackson Laboratory (Bar Harbor, Maine, USA). They were bred and kept in the animal unit of Medical Inflammation Research in Lund. The animals were kept in a climatecontrolled environment (temperature and humidity) with 12 -hour cycles of light/dark and sound. They were housed 2-3 rats or 5-7 mice in each polystyrene cage containing wood shavings. They were allowed water ad libitum and were fed standard rodent chow. They were found to be free from common pathogens including Sendai virus, Hantaan virus, coronavirus, reovirus, cytomegalovirus, and mycoplasma pulmonis. Animals in all experiments were immunized at 8-13 weeks of age and were age matched before the experiments.

Induction and evaluation of disease. Bovine CMP was purified as described previously $(36,37)$. The protein was dissolved in $5 \mathrm{M}$ guanidine- $\mathrm{HCl}$ at a concentration of $5 \mathrm{mg} / \mathrm{mL}$. The rats were immunized intradermally at the base of the tail with a dilution of the stock solution in PBS that was emulsified with incomplete Freund's adjuvant (Difco Laboratories, Detroit, Michigan, USA) 
Table 1

Scoring of respiratory distress in rats

Scoring grade

Hissing under Inspiratory Abnormal breathing phonation

stridor

pattern at exercise ${ }^{A}$

1

2

3

4

5

${ }^{A}$ Abnormal breathing was considered to be when inspiratory retraction of the thoracic wall and/or lifting of the shoulders were observed as a sign of auxiliary inspiratory muscle activities.

at a $1: 1$ ratio to the protein solution. The final CMP concentration was $500 \mathrm{mg} / \mathrm{mL}$. Rats were immunized with 150 or $75 \mu \mathrm{g}$ of CMP. Control rats were injected with the same chemicals and amounts, omitting the CMP protein. Mice were immunized with the same procedure, but with a concentration of $1,000 \mu \mathrm{g} / \mathrm{mL}$. Each mouse received $100 \mu \mathrm{g}$ intradermally, emulsified in complete Freund's adjuvant (Difco Laboratories).

The rats were evaluated for disease once or twice a day during the onset period, and once a day thereafter. They were scored for respiratory distress according to a scoring scale from 0 to 5 (Table 1 ). Abnormal breathing was considered to be when inspiratory retraction of the thoracic wall and/or lifting of the shoulders were observed as a sign of auxiliary inspiratory muscle activities. To test whether physical activity increased the respiratory distress, the animals were kept running outside the cage for 1 to 2 minutes. Mice were scored in a similar way as the rats, with some minor changes regarding scores $2-4$ : score 2 was inspiratory stridor in periods; score 3 was inspiratory stridor continuously; and score 4 was inspiratory stridor continuously and abnormal breathing. Special notes were also taken as to involvement of nose, eyes, ears, joints, and kidney (see Results).

Quantification of antibody response. The animals were bled regularly, beginning with once a week. Blood was collected from the tail vein, and the sera were stored at $-20^{\circ} \mathrm{C}$ until assayed. To investigate antibody response, ELISA was performed. Microtiter plates (Immunolon 2; Dynatech Laboratories, Chantilly, Virginia, USA) were coated with $10 \mu \mathrm{g} / \mathrm{mL}$ of CMP in PBS and $0.02 \%$ sodium azide overnight at $4^{\circ} \mathrm{C}$. The plates were washed in washing buffer (Tris-Cl 0.1 M, 0.05\% Tween-20), and incubated for 2 hours at room temperature with sera diluted 1:100 in PBS buffer (PBS, 0.05\% Tween-20, and $0.02 \%$ sodium azide). Washing was repeated, and the plates were then incubated for another 2 hours with conjugates detecting IgG, donkey anti-rat (Jackson ImmunoResearch Laboratories Inc., West Grove, Pennsylvania, USA), IgM, IgG1, IgG2a, IgG2b, and goat antirat (Southern Biotechnology Associates, Birmingham, Alabama, USA). All conjugates were labeled with alkaline phosphatase. Other coating proteins used were native CII, CIX, CXI, and COMP purified as earlier described (19, 38-40), with all proteins originating from the rat. The same coating procedures as for CMP were used except that the sera were diluted 1:10 and ELISA was performed on sera from day 41. The microtiter plates were developed with nitrophenyl phosphate as the substrate, and the amount of antibody was estimated as absorbance at $405 \mathrm{~nm}$ by using a Titertek Multiscan PLUS Spectrophotometer (Flow Laboratories Inc., McLean, Virginia, USA). The titer values obtained at OD 1.0 were expressed as relative titer values compared with a positive control consisting of pooled sera from 2 female LEW.1A rats immunized with $150 \mu \mathrm{g}$ of CMP. Throughout the experiments, this pool was used for reference in all analyzed ELISA plates. As positive controls for CII, CIX, CXI, and COMP antibody measurements, we used sera from arthritic rats immunized with $150 \mathrm{mg}$ CIX (female rat, LEW.1W, day 56), CII (female rat, DA, day 21), COMP (female rat, E3, day 19), and rat antibodies to CXI, purified by $\left(\mathrm{NH}_{4}\right)_{2} \mathrm{SO}_{4}$ precipitation and affinity chromatography, at a concentration of $1 \mathrm{mg} / \mathrm{mL}$. Titers were obtained at OD 1.5 (CII) and 0.5 (CIX and COMP). All tests were carried out in duplicate, and the variation did not exceed $10 \%$.

Histological and immunohistopathological examination. All animals were subjected to histological examination for pathology. Tissue samples for light microscopy were processed according to standard procedures. Briefly, the tissue samples were fixed in 4\% paraformaldehyde for 24 hours, dehydrated and embedded in paraffin, sectioned at $4 \mu \mathrm{m}$, and stained with hematoxylin and erythrosin. Mast cells and newly formed cartilage (i.e., irregular cartilage tissue outside the original and normal cartilaginous structures) were detected after staining with safranin $\mathrm{O}$. The sections were evaluated according to a scoring system, as follows: $\mathrm{A}=$ active phase; $\mathrm{H}=$ healing phase $\mathrm{N}=$ normal tissue; $+\mathrm{A}=$ scattered inflammatory cells; ${ }^{++} \mathrm{A}=$ inflammatory infiltrates; ${ }^{+++} \mathrm{A}=$ massive inflammation with pannus formation and/or cartilage erosion; $+\mathrm{H}=$ new formation of connective tissue, low level of new formation of cartilage; $++\mathrm{H}=$ new formation of cartilage; and $+++\mathrm{H}=$ large areas of new formation of cartilage, disruption of the tissue structures.

For immunohistochemical studies, the tissue samples were immediately dissected and frozen in iso-pentane on dry ice. The samples were stored at $-70^{\circ} \mathrm{C}$ until cryosectioned at $6 \mu \mathrm{m}$ at $-26^{\circ} \mathrm{C}$. Antibodies used as primary reagents were OX35 (CD4) (41) and OX8 (CD8) (42), purified on a GammaBind Plus Sepharose Gel (Pharmacia LKB Biotechnology, Uppsala, Sweden); R73 ( $\alpha \beta$-TCR) (43), also purified on a GammaBind Plus Sepharose Gel; and ED1 (maturing macrophages; Novakemi AB, Enskede, Sweden), ED2 (tissue 

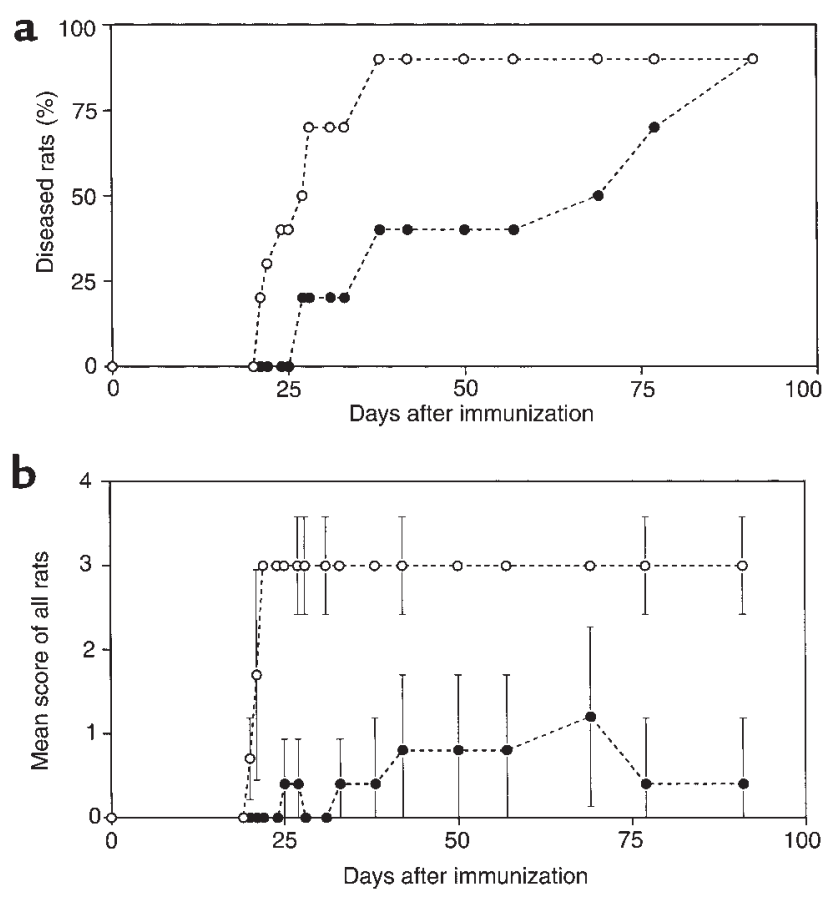

Figure 2

Blocking of $\alpha \beta$ TCR with mAb's (R73). LEW.1F female rats, immunized with $150 \mu \mathrm{g}$ of CMP, were treated with either PBS (open circles) or PBS + R73 (filled circles). Incidence (a) and mean clinical score \pm SD (b). Clinical scores of respiratory distress. See Methods.

macrophages; Novakemi AB), OX19 (CD5) (44), and OX6 (MHC II) (45). Staining was performed according to established protocols (46). Eighteen female rats were used, 1 slide per animal, with 2 sections per slide analyzed for numbers of cells per square millimeter. Three different sized fixed areas on each slide were counted using a Zeiss microscope (Carl Zeiss GmbH, Eching, Germany) with an image analysis system. All slides were analyzed in a blinded fashion.

A polyclonal antibody against bovine $\mathrm{CMP}$ was raised in rats, and immunoglobulin was purified by $\left(\mathrm{NH}_{4}\right)_{2}$ $\mathrm{SO}_{4}$ precipitation (47). The immunoglobulin antibody was labeled with biotin and used for staining as already described here, with minor protocol modifications.

Antibody treatment. Female 8- to 12 -week-old rats of LEW.1F strain were immunized with $150 \mu \mathrm{g}$ of CMP. R73 and OX8 antibodies were purified from hybridoma supernatants as described previously $(48,49)$. Int he first experiment, 1 group was treated with $500 \mu \mathrm{g}$ of R73 in 1 $\mathrm{mL}$ PBS injected intraperitoneally on days 14 and 15 , just before expected onset of breathing disturbances. As controls, rats were injected with an equal volume of PBS. The treatments were repeated 6 days later on days 20 and 21 . In the second experiment, a group of 8 animals was treated with $500 \mu \mathrm{g}$ of purified mAb against CD8 (OX8) in 1.5 $\mathrm{mL}$ of PBS injected intraperitoneally on days 15 and 16 , according to described protocols (49). Eight control rats were injected with a corresponding volume of PBS. All animals were bled on days $0,22,30$, and 49 for detection of antibody response and for flow cytometric analyses.
Statistical analysis. Mann Whitney $U$ test was used for disease scores, whereby only affected animals were considered. Student's unpaired $t$ test (2-tailed) was used for antibody levels and for cell numbers in sections. Incidence of disease was analyzed with $\chi^{2}$ test. If not indicated otherwise, a level of $P<0.05$ was considered significant.

\section{Results}

CMP-immunized rats and mice developed respiratory distress. In the first experiment, female rats of the DA, E3, and LEW strains - as well as the LEW congenic strains LEW.1A, LEW.1C, LEW.1F, LEW.1D, LEW.1N, and LEW.1W - were immunized with $150 \mu \mathrm{g}$ of CMP in mineral oil. On day 16 after immunization, LEW.1F rats showed respiratory distress that worsened to scores 4 and 5 in a few days. During the following weeks, 36\% of the animals of this strain developed severe inspiratory stridor and cyanosis and had to be sacrificed. The symptoms in the remaining LEW.1F rats were those of an ongoing disease with mild relapses, although they tended to stabilize on a scoring level of 2 . Another sensitive strain was the LEW, which had a respiratory distress incidence of $88 \%$ but with a later onset than the LEW.1F strain. These rats continued to develop more severe symptoms with time, and a few of them finally had to be sacrificed before the end of the experiment (Table 2). One of the LEW rats showed severe hematuria and proteinuria. All other rats were negative as measured with a dipstick. Other susceptible strains were the LEW.1A and the LEW.1D, which, like LEW.1F and LEW, showed similar disease course with 1 or 2 relapses of breathing disturbances. Almost all rats showed swollen noses and/or epistaxis.

To investigate whether the disease was also inducible in the mouse, we selected 3 strains known to be susceptible to various autoimmune diseases: NOD mice, which are susceptible to developing diabetes; DBA/1 mice, which are susceptible to CIA; and B10.RIII mice, which are susceptible to both chronic experimental allergic encephalomyelitis and CIA (50-52). The mice were immunized with $100 \mu \mathrm{g}$ of CMP. A proportion (40\%) of the DBA/1 mice developed respiratory distress with similar disease course, including a relapse around day 80 after immunization, and demonstrated similar histopathology as the susceptible rat strains. The NOD and the B10.RIII mice did not show any clinical signs (Table 3 ).

No signs of inflammation in the ears, eyes, tail, joints, or other parts of the body were found in any rat or mouse upon clinical examination.

Genetic influence on disease. The incidence of symptoms clearly showed predominance in susceptibility for the LEW background (Table 2). Neither the DA nor the E3 rat showed any of the signs evaluated in the scoring system. Differences in disease susceptibility among the LEW congenic strains (f, $\mathrm{l}, \mathrm{d}$, and a were susceptible, whereas $\mathrm{c}, \mathrm{n}$, and $\mathrm{u}$ were resistant) demonstrated the importance of the MHC region. 
Table 2

Susceptibility of different strains of female rats when immunized with $150 \mu \mathrm{g}$ of CMP

\begin{tabular}{|c|c|c|c|c|c|c|c|c|}
\hline Strain & RT1 & Incidence & $\begin{array}{c}\text { Mean day } \\
\text { of onset }\end{array}$ & $\begin{array}{l}\text { Mean } \\
\text { score }^{A}\end{array}$ & $\begin{array}{c}\text { Mean maximal } \\
\text { score }^{A}\end{array}$ & $\begin{array}{l}\text { Mean day } \\
\text { of score } 5^{A}\end{array}$ & $\begin{array}{l}\text { Microscopic } \\
\text { score nose } \mathrm{e}^{\mathrm{A}, \mathrm{B}}\end{array}$ & $\begin{array}{l}\text { Microscopic } \\
\text { score larynx } x^{A, B}\end{array}$ \\
\hline DA & av1 & $0 / 8$ & - & - & - & - & $+\mathrm{A},+\mathrm{H}$ & $\mathrm{N}$ \\
\hline E3 & $\mathrm{u}$ & $0 / 8$ & - & - & - & - & $++\mathrm{A},+\mathrm{H}$ & $+\mathrm{A},+\mathrm{H}$ \\
\hline LEW & I & $7 / 8$ & $55 \pm 35$ & 2.7 & $3.5 \pm 1.1$ & $70 \pm 20$ & $++\mathrm{A},+++\mathrm{H}$ & $+++\mathrm{A},+++\mathrm{H}$ \\
\hline LEW.1A & a & $6 / 8$ & $57 \pm 27$ & 2.1 & $2.8 \pm 0.7$ & - & $++\mathrm{A},+++\mathrm{H}$ & $+++\mathrm{A},+++\mathrm{H}$ \\
\hline LEW.1C & c & $0 / 4$ & - & - & - & - & $+\mathrm{A},++\mathrm{H}$ & $+\mathrm{H}$ \\
\hline LEW.1D & $d$ & $4 / 10$ & $32 \pm 12$ & 2.0 & $2 \pm 0$ & - & $+\mathrm{A},++\mathrm{H}$ & $++\mathrm{A},+\mathrm{H}$ \\
\hline LEW.1F & f & $12 / 14$ & $26 \pm 16$ & 2.0 & $3.9 \pm 1.2$ & $19 \pm 2$ & $+++\mathrm{A},++\mathrm{H}$ & $+++\mathrm{A},+\mathrm{H}$ \\
\hline LEW.1N & $n$ & $0 / 4$ & - & - & - & - & $+++\mathrm{A},+\mathrm{H}$ & $\mathrm{N}$ \\
\hline LEW.1W & u & $0 / 9$ & - & - & - & - & $+\mathrm{A},+\mathrm{H}$ & $+\mathrm{A},+\mathrm{H}$ \\
\hline Control $1^{\mathrm{C}}$ & c & $0 / 18$ & - & - & - & - & $\mathrm{N}$ & $\mathrm{N}$ \\
\hline Control 2D & D & $0 / 18$ & - & - & - & - & $\mathrm{N}$ & $\mathrm{N}$ \\
\hline
\end{tabular}

Mean values \pm SD. At evaluation of respiratory distress, only symptoms lasting for more than 5 days were considered; mild hoarseness during 1 day was seen in $2 \mathrm{E} 3$ rats. ${ }^{\mathrm{A} C l i n i c a l}$ scores of respiratory distress and histological scores. See Methods. ${ }^{\mathrm{B}}$ Mean value of histological score when analyzing all animals of each strain. Sections were analyzed close to onset day in 50\% of the affected animals and at the end of the experiment on day 120 in the remaining ones. ${ }^{\mathrm{C} N o n-}$ immunized rats. Two animals of each strain were used, and 1 of these was analyzed histopathologically. DRats immunized with the same chemicals and amounts as the noncontrol rats, except for CMP. Two animals of each strain were used; 1 of these was analyzed histopathologically. Data shown are from 2 identically performed experiments.

The LEW.1A rats, which share MHC class II genes with DA, were susceptible, showing that non-MHC class II genes are also of importance.

Gender influence on disease. For further studies, we selected the LEW.1F strain, as they were the most susceptible. To investigate a possible difference by gender, sex-matched LEW.1F rats were immunized with either 150 or $75 \mu \mathrm{g}$ of CMP. The results show that females were affected at a higher incidence and severity. This was true for immunization of both concentrations (Table 4). However, females immunized with the lower dose showed a later onset and a lower score.

Histology. All rats immunized with CMP were found to have inflammatory lesions in close connection to the cartilage in the nasal septum, even in animals not showing any sign of respiratory distress. Control rats showed no sign of inflammation in any experiment. An example of sections from affected noses in acute and chronic phases are shown in Figure 1, a and b. Severe histopathological findings in the thyroid and cricoid cartilage and its surrounding connective tissues were restricted to those animals that had shown signs of respiratory distress (Table 2 and Figure 1, c and $d$ ). In the acute phase, cartilage erosions and a massive invasion of inflammatory cells were seen in the larynx, and especially in epiglottic cartilage, leading to a lethal swelling in the upper airways. The most severe changes in the larynx were seen in the LEW, LEW.1A, and LEW.1F rats, which all reached the highest histological score in active and/or chronic phase and which correlated well with the clinical scores. All DA rats showed at least some degree of severe fibrosis in the kidneys, and 1 of them had signs of a fully developed glomerulonephritis. Control DA rats showed similar pattern of fibrosis in the kidneys. One E3 and $1 \mathrm{LEW}$ rat were also found to have inflammatory infiltrates in the kidneys but restricted to the tubuli.
The infiltrates, which were seen in close association to cartilage, as well as in the kidney, consisted mainly of neutrophils but also macrophages, lymphocytes, and mast cells. Laryngeal tissue samples from the acute phase in the LEW.1F female rats presented a much higher number of eosinophils compared with rats in the chronic phase, as well as compared with control rats.

Sections were also analyzed from the inner and outer ear, the eye, the lung, the joint, and the xiphisternal cartilage, but no sign of inflammation was found in these samples. Upon evaluation of male and female responses, a good correlation was found between the clinical scores and the histological observations in laryngeal tissues. The female rats showed the most severe changes in the nose and the larynx (Table 4). Immunohistochemical staining for macrophages and MHC II and T cells was done on samples of the larynx and the nose, with comparative analysis of sections from days 18 and 120 (Table 5). In the acute phase of the disease, the number of $\mathrm{CD}^{+}$ cells, macrophages (OX 35), and $\mathrm{CD}^{+}$cells (OX8) was significantly higher in the larynx than in the nose, indicating the larynx as the main target. Notably, the number of $T$ cells remained high in the chronic phase in the larynx, indicating a chronic inflammation, whereas $\mathrm{T}$ cells were not detectable in the chronically affected nose. Furthermore, the level of MHC class II expression in the chronic phase was significantly higher in the larynx than in the nasal tissue.

Similar histopathology as described for the rats developed in the mice, but with some important differences. The occurrence of inflammatory changes in the nose was rare, and only mild affections were detected. Most DBA/1 mice showed signs of healed inflammation, and 2 of them had minor areas of cartilage erosions. One third of the NOD mice showed very mild involvement of the nose and the larynx. The affections of the laryn- 
Table 3

DBA/1J, NOD, and B10.RIII male mice immunized with $100 \mu \mathrm{g}$ of CMP

\begin{tabular}{lccccc}
\hline Incidence & $\begin{array}{c}\text { Mean day } \\
\text { of onset }\end{array}$ & $\begin{array}{c}\text { Mean maximal } \\
\text { score }\end{array}$ & $\begin{array}{c}\text { Microscopic } \\
\text { score nose }\end{array}$ & $\begin{array}{c}\text { Microscopic } \\
\text { score larynx }\end{array}$ \\
DBA 1 1J & $4 / 10$ & $37 \pm 3$ & $3.3 \pm 0.5$ & $+\mathrm{A}$ & $+\mathrm{A},++\mathrm{H}$ \\
$\mathrm{NOD}$ & $0 / 10$ & - & - & $\mathrm{N}$ & $\mathrm{N}$ \\
$\mathrm{B} 10$. RIII & $0 / 10$ & - & - & $\mathrm{N}$ & $\mathrm{N}$ \\
Control $1^{\mathrm{C}}$ & $0 / 15$ & - & - & $\mathrm{N}$ & $\mathrm{N}$ \\
Control $2^{\mathrm{D}}$ & $0 / 15$ & - & - & $\mathrm{N}$ & $\mathrm{N}$
\end{tabular}

Mean values \pm SD. At evaluation of respiratory distress, only symptoms lasting for more than 5 days were considered. ${ }^{A}$ Clinical scores of respiratory distress and histological scores. See Methods. ${ }^{B}$ Mean value of histological score when analyzing all animals of each strain. Sections were analyzed at the end of the experiment, on days 112-115. CNonimmunized mice. Five mice of each strain were used; 2 of them were analyzed histopathologically. DMice immunized with the same chemicals and amounts as the noncontrol mice, except for CMP. Five mice of each strain were used; 2 of them were analyzed histopathologically.

gotracheal region were overall milder when compared with those in the rat, but the inflammatory infiltrates correlated well with the clinical symptoms (Table 3). Immunolocalization of CMP. To confirm the specificity for CMP and the target of the inflammatory attack, cartilage tissues from immunized and nonimmunized rats were stained with CMP-specific antibodies. Tissues from the ear, the joint, the nose, and the larynx from 3 different strains (DA, E3, and LEW.1F) were investigated. All 3 strains, CMP-immunized and nonimmunized, presented positive staining in the larynx and nose but not in the joints or in the ear (Figure 1, e and $\mathrm{f}$ ). Staining for CMP was most pronounced in the superficial layer of the cartilage tissues.

Immune response. The antibody response was investigated for all strains studied, in rats and mice, but no clear correlation between susceptibility and disease development and antibody levels could be found. All rats presented a high antibody titer against bovine CMP compared with the controls, which expectedly showed no response. The level of total specific IgG peaked between day 28 and day 48 and then declined gradually in all strains. Surprisingly, the maximum level was highest in the disease-resistant $\mathrm{E} 3$ rats and lowest in the disease-susceptible LEW.1F rats. No significant differences in relative frequencies of the various immunoglobulin isotypes (IgM, IgG, IgG1, IgG2a, and $\operatorname{IgG} 2 \mathrm{~b}$ ) were seen between the rat strains or with disease. In fact, there was a tendency toward lower overall levels in the highly susceptible LEW.1F rats and higher levels in the resistant E3 rats. Comparison of the total levels of IgG in males and females and in animals immunized with different amounts of CMP followed the pattern of the results of clinical and histological evaluation (Table 4).

To investigate whether the immune response might involve other cartilage antigens, we analyzed serum antibody levels to CII, CIX, CXI, and COMP. Among the disease-affected rats, $17 \%$ had positive titers to CII. About $60 \%$ of the diseased rats of the LEW and LEW.1A strains responded against CIX, and 1 individual responded with high values against both CII and CIX. Fifteen percent of the nondiseased rats (E3, LEW.1W, DA, and LEW.1N strains) also showed antibodies against CIX. The DA rats showed significantly higher titers of IgG antibodies directed against COMP compared with all other strains. However, all antibody responses found against the cartilage-specific proteins described earlier here only reached 10-100 times lower titers than those found against CMP. No antibody response was detected against CXI in any strain.

T-cell dependency. Because the disease was found to be controlled by MHC, we wanted to assess its T-cell dependency. An experiment was designed in which the $\mathrm{T}$ cells were blocked in vivo, after they had primed the B-cell response but before they mediated effector functions in the target tissue. Thus, 2 weeks after immunization, LEW.1F rats were injected with an $\alpha \beta$ TCR-specific antibody known to block the function of $\alpha \beta$ T cells $(48,53)$ efficiently. The R73-treated rats developed less severe disease, as seen by a delayed onset and lowered maximal scores (Table 6 and Figure 2). Consequently, the inflammation in the larynx was less

Table 4

Susceptibility of male versus female LEW.1F rats, immunized with $150 \mu \mathrm{g}$ versus $75 \mu \mathrm{g}$

\begin{tabular}{|c|c|c|c|c|c|c|c|}
\hline Mic & $\begin{array}{l}\text { licrograms of CMP } \\
\text { immunized }\end{array}$ & Incidence & $\begin{array}{l}\text { Mean day } \\
\text { of onset }\end{array}$ & $\begin{array}{l}\text { Mean maximal } \\
\text { score }^{A}\end{array}$ & $\begin{array}{l}\text { Mean day } \\
\text { of score } 5^{A}\end{array}$ & $\begin{array}{l}\text { Microscopic } \\
\text { score nose } \mathrm{e}^{\mathrm{A}, \mathrm{B}}\end{array}$ & $\begin{array}{c}\text { Microscopic } \\
\text { score larynx } x^{A, B}\end{array}$ \\
\hline Female & 150 & $12 / 14$ & $26 \pm 16$ & $3.9 \pm 1.2$ & $19 \pm 2$ & $+++\mathrm{A},++\mathrm{H}$ & $+++\mathrm{A},+\mathrm{H}$ \\
\hline Male & 150 & $4 / 8$ & $49 \pm 15$ & $2.2 \pm 0.4$ & - & $+\mathrm{A},+\mathrm{H}$ & $++\mathrm{A},+\mathrm{H}$ \\
\hline Female & 75 & $6 / 8$ & $49 \pm 19$ & $2.7 \pm 0.5$ & - & $+++\mathrm{A},++\mathrm{H}$ & $+++\mathrm{A},+\mathrm{H}$ \\
\hline Male & 75 & $2 / 8$ & $27 \pm 8$ & $2 \pm 0$ & - & $+\mathrm{A},+\mathrm{H}$ & $++\mathrm{A}$ \\
\hline Female controle & - & $0 / 8$ & - & - & - & $N$ & $\mathrm{~N}$ \\
\hline Male controlc & - & $0 / 8$ & - & - & - & $\mathrm{N}$ & $\mathrm{N}$ \\
\hline
\end{tabular}

Mean values \pm SD. At evaluation of clinical scores, only symptoms lasting for more than 5 days were considered. ${ }^{A}$ Clinical scores of respiratory distress and histological scores. See Methods. BMean value of histological score when analyzing all animals of each strain. CRats immunized with the same chemicals and amounts as the noncontrol rats, except for CMP. Sections were analyzed close to onset day in $50 \%$ of the affected animals and at the end of the experiment on day 120 in the remaining ones. Data shown are from 2 identically performed experiments. 
Table 5

Immunohistochemical staining of the larynx and the nose

\begin{tabular}{|c|c|c|c|c|c|c|c|c|}
\hline & $\begin{array}{c}\text { Tissue } \\
\text { (number of rats) }\end{array}$ & ED1 & ED2 & OX6 & OX35 & R73 & OX19 & OX8 \\
\hline \multirow[t]{3}{*}{ Larynx } & Normal (2) & 0 & 0 & $130 \pm 0$ & 0 & 0 & 0 & 0 \\
\hline & Day 18 p.i. (3) & $985 \pm 63^{A}$ & $707 \pm 65$ & $1,074 \pm 34^{\mathrm{B}}$ & $778 \pm 110^{\mathrm{D}}$ & $518 \pm 44^{\mathrm{B}}$ & $505 \pm 12^{\mathrm{A}}$ & $588 \pm 152^{\mathrm{A}, \mathrm{C}}$ \\
\hline & Day 120 p.i. (4) & $467 \pm 136^{A}$ & $669 \pm 194$ & $771 \pm 152^{\mathrm{B}, \mathrm{C}}$ & $506 \pm 171$ & $294 \pm 116^{B, D}$ & $266 \pm 76^{\mathrm{A}, \mathrm{D}}$ & $37 \pm 23^{A, C}$ \\
\hline \multirow[t]{3}{*}{ Nose } & Normal (2) & 0 & $92 \pm 56$ & 0 & $127 \pm 93$ & 0 & 0 & 0 \\
\hline & Day 18 p.i. (3) & $1,119 \pm 229^{A}$ & $690 \pm 31$ & $922 \pm 279^{B}$ & $354 \pm 65^{\mathrm{D}}$ & $465 \pm 82^{A}$ & $170 \pm 163$ & $193 \pm 7^{A, C}$ \\
\hline & Day 120 p.i. (4) & $259 \pm 107^{A}$ & $652 \pm 149$ & $563 \pm 12^{B, C}$ & $321 \pm 58$ & $0^{A, D}$ & $0^{\mathrm{D}}$ & $0^{\mathrm{A}, \mathrm{C}}$ \\
\hline
\end{tabular}

Sections were chosen according to their histopathological scores, which reached the highest values, i.e., $+++\mathrm{A}$ (acute phase) and $+++\mathrm{H}$ (chronic phase). Female rats of the LEW, LEW.1A, and LEW.1F strains were used. Mean values \pm SD of numbers of cells per square millimeter, calculated from 3 different areas on each slide (2 sections), are presented. Measurements were done in the inflamed area/infiltrate and pannus formation and always in close contact to the cartilage. p.i., post immunization. ${ }^{A} P<0.01$ when comparing identical tissue from acute and chronic phase. ${ }^{B} P<0.05$ when comparing identical tissue from acute and chronic phase. ${ }^{C} P<0.05$ when comparing laryngeal and nasal tissue from the same phase (acute or chronic). ${ }^{D} P<0.01$ when comparing laryngeal and nasal tissue from the same phase (acute or chronic).

pronounced in the R73-treated rats during the acute phase. In the chronic phase, 95 days after immunization, an effect of the R73 treatment was still seen, resulting in lower score. Importantly, the R73 treatment did not affect the antibody response to CMP. These results indicate that the $\alpha \beta$ T cells play a crucial role in priming the immune response and mediating the effector phase.

Upon immunohistochemical analysis (Table 5), the ratio of $\mathrm{OX} 8 / \mathrm{OX} 35$, reflecting the relationship between $\mathrm{CD}^{+}$and $\mathrm{CD} 4^{+} \mathrm{T}$ cells, was found to be quite high. As a follow-up to these results, the role of $\mathrm{CD}^{+}$ $\mathrm{T}$ cells in chondritis development was investigated by treating CMP-immunized rats with an anti-CD8 $\mathrm{mAb}$ (OX8) known to deplete CD8 ${ }^{+} \mathrm{T}$ cells effectively (46), just before expected disease onset. No difference could be detected in any of the parameters studied: onset, clinical scoring, histological scoring, or antibody response (Table 6). Thus, most likely, the pathogenic $\mathrm{T}$ cells are $\mathrm{CD}^{+}{ }^{+} \mathrm{MHC}$ class II-restricted $\alpha \beta$ T cells.

\section{Discussion}

Immunization with the cartilage-specific protein CMP induced an immune response and clinical symptoms different from those any of the previously investigated immunogenic cartilage proteins such as CII, CIX, CXI, link protein, aggrecan, and COMP (6-8, 16-19, 54). Immunization with CMP did not affect the joints, which were the primary sites of reaction upon immunization with cartilage collagens, aggrecan, and COMP. Instead, it affected those organs in which the protein was originally found in normal tissues, i.e., trachea and nasal septum (30).

Rats immunized with CMP presented severe inspiratory stridor. In addition, almost all the animals showed an affected nose, clinically scored as epistaxis and/or a considerable swelling. The histological analysis demonstrated an aggressive inflammatory attack and severe cartilage erosion correlating to respiratory distress. The observed clinical symptoms, together with the histological findings, are strongly reminiscent of those observed in humans with RP $(9,55)$. They also meet the inclusion criteria used when analyzing patients with RP: "proven inflammatory episodes, involving at least 2 of 3 sites (auricular, nasal, laryngotracheal cartilage) or one of these together with 2 other manifestations...” (11). The occurrence of inflammatory infiltrates in the kidneys of the rats is also well in line with a kidney functional disturbance seen in about $20 \%$ of the patients with RP (56). CMP-induced chondritis represents a new animal model for RP.

The main infiltration of inflammatory cells causing respiratory distress was found in the larynx, close to the epiglottic cartilage, indicating a predilection for the elastic (epiglottis) rather than the hyaline cartilage. Furthermore, during the acute phase of the disease, we observed a significantly elevated number of CD $4^{+}$and $\mathrm{CD}^{+} \mathrm{T}$ cells in the larynx compared with the nose. The T cells remained in high numbers in the larynx during the chronic phase, whereas they were not detectable in the nose during the chronic phase. This is in line with the theory that CMP has a role in development of RP, wherein the cardinal symptoms result from inflammation of the selected cartilage-containing tissues. Inflammation of the same cartilage has been reported previously in mice and rats (57-60), where auricular chondritis developed spontaneously or subsequent to peripheral joint arthritis in CII-immunized animals. However, a possible explanation to the CII-induced chondritis is that the inflammatory attack was a secondary effect of the arthritis and the immune reactions directed toward CII or other cartilage proteins released during joint cartilage destruction.

CMP-induced chondritis was found to be genetically controlled by the $\mathrm{MHC}$ region and to be dependent on functional $\alpha \beta$, presumably CD $4^{+}$, T cells. Furthermore, there was a higher susceptibility among female rats. These results are analogous to previously published data of several rat models for arthritis (induced by mycobacteria, pristane, mineral oil, avridine, and CII) (61-63). A striking dissimilarity with the arthritis models is, however, the absence of symptoms in the DA rat, indicating that the non-MHC genetic control differs between arthritis and polychondritis. 
Table 6

Differences between female LEW.1F rats immunized with $150 \mu \mathrm{g}$ of CMP when treated with PBS, PBS + antibodies against the $\alpha \beta$ TCR (R73), or PBS + antibodies against CD8 (OX8)

\begin{tabular}{|c|c|c|c|c|}
\hline & Incidence & Mean day of onset ${ }^{A}$ & Mean maximal score ${ }^{A, B}$ & $\begin{array}{l}\text { Relative titers } \\
\text { CMP-specific } \lg C\end{array}$ \\
\hline \multicolumn{5}{|l|}{ Experiment 1} \\
\hline \multirow[t]{2}{*}{ Control rats } & $9 / 10$ & $27 \pm 6$ & $3.5 \pm 1.2$ & $0.86 \pm 0.06$ \\
\hline & & $P<0.05$ & $P<0.05$ & $P>0.05$ \\
\hline R73-treated rats ${ }^{\mathrm{D}}$ & $9 / 10$ & $57 \pm 26$ & $2 \pm 0$ & $0.86 \pm 0.09$ \\
\hline \multicolumn{5}{|l|}{ Experiment 2} \\
\hline \multirow{2}{*}{ Control rats } & $8 / 8$ & $30 \pm 15$ & $2.9 \pm 1.8$ & $0.87 \pm 0.12$ \\
\hline & & $P>0.05$ & $P>0.05$ & $P>0.05$ \\
\hline OX 8-treated rats ${ }^{\mathrm{D}}$ & $7 / 8$ & $31 \pm 14$ & $2.8 \pm 1.7$ & $0.93 \pm 0.15$ \\
\hline
\end{tabular}

Mean values \pm SD. ${ }^{A}$ Only affected animals were considered. ${ }^{B}$ Clinical scores of respiratory distress. See Methods. ${ }^{C}$ Sera from day 49 . Titers expressed as $10^{\log }$, DBlood samples from days $0,22,30$, and 49 were stained for R73 and OX8, respectively, and analyzed on a FACSort flow cytometer (Becton Dickinson Immunocytometry Systems, San Jose, California, USA) to confirm the elimination of R73- and OX8-reactive cells. No cells staining for R73 or OX8 could be found in peripheral blood after antibody treatment.

The fact that the antibody response did not correlate with clinical symptoms at any time during the disease course again opens possibilities that effector pathways other than those mediated by antibodies are of more critical importance, with regard to both initiation and maintenance of the disease. This contrasts to CIA, wherein antibodies have been documented to be pathogenic and to play a critical role in the disease course (64). However, in the chronic CIA in DA rats induced with autologous CII, the $\mathrm{T}$ cells also play a role in the effector phase (48), in analogy with the presently described CMP-induced polychondritis. Interestingly, in this new model, $17 \%$ of the affected animals developed an antibody response to CII. Because this response most likely is elicited by CII released as a result of destruction of the target cartilage, it reflects an ongoing active autoimmune process that is also seen in up to $50 \%$ of the patients with RP (65). Our findings provide direct evidence of the diversity of collagens and other cartilage components, and their unique immunoproperties. The different targets observed with different proteins, and the diverse pathological pictures seen, raise new questions regarding factors that govern autoimmune disease. Although CII and COMP are present in both articular cartilage and the cartilage of the respiratory tract, no symptoms have been observed from the latter site in either CII- or COMP-induced experimental disease. In addition, the animals immunized with CMP showed no symptoms from joints, although antibodies to collagen and COMP were detected in several cases.

Future studies of CMP-induced disease will include disorders with a complex of symptoms similar to RP, such as Wegener's granulomatosis, which, like RP, affects the airways, the kidneys, and the nose (66); and Churg-Strauss syndrome, with kidney affections and airway eosinophilia (67). Our results will also contribute to the discussion about the etiology of "intrinsic" asthma, especially the chronic phase of the disease. One possibility could be that the chronicity of asthma is maintained by an autoimmune mechanism as a secondary effect of cartilage destruction in the airways, and, if so, the importance of CMP is obvious. The involvement of CMP in the pathogenesis of asthma has, however, not yet been investigated.

In conclusion, an animal model for RP (matrilin1 -induced RP), has been established. The results suggest that different cartilage proteins are involved in RA and RP. With respect to the understanding of the pathogenesis of RA, such a possibility is of importance, as the predilection for diarthrodial cartilaginous joints is not understood. Of interest, however, is the fact that approximately one third of severe RA cases have involvement not only of peripheral joints but also of the larynx, although breathing obstruction is rare (68, 69). In addition, increased levels of CMP are seen in a proportion of patients with RA (31). Our findings will be valuable in further investigations of RA and RP to reveal the main target of the destructive inflammation in the joints, and to provide essential background for understanding the role of different cartilage components in autoimmune diseases affecting cartilage.

\section{Acknowledgments}

We thank L. Lindström, M. Persson, Y. Sjöö, and C. Palestro for taking care of the animals, and B. Jonson (Department of Clinical Physiology, Lund University) for critical evaluation and advice concerning the clinical descriptions of airway diseases. The work was supported by grants from the Anna Greta Crafoord Foundation for Rheumatological Research, King Gustaf V:s 80-year Foundation, the Kock and Österlund Foundations, the Swedish Association against Rheumatism, the Swedish Foundation for Strategic Research, and the Swedish Medical Research Council.

\footnotetext{
1. Ebringer, R., Rook, G., Swana, G.T., Bottazzo, G.F., and Doniach, D. 1981. Autoantibodies to cartilage and type II collagen in relapsing polychondritis and other rheumatic diseases. Ann. Rheum. Dis. 40:473-479.

2. Foidart, J.M., et al. 1978. Antibodies to type II collagen in relapsing polychondritis. N. Engl. J. Med. 299:1203-1207.

3. Svenson, K.L.G., et al. 1984. Cyclosporin A treatment in a case of relaps-
} 
ing polychondritis. Scand. J. Rheumatol. 13:329-333.

4. Charrièra, G., et al. 1988. Antibodies to type I, II, IX and XI collagen in serum of patients with rheumatic diseases. Arthritis Rheum. 31:325-332.

5. Morgan, K., et al. 1989. A longitudinal study of anticollagen antibodies in patients with rheumatoid arthritis. Arthritis Rheum. 32:139-145.

6. Karopoulos, C., Rowley, M.J., Ilic, M.Z., and Handley, C.J. 1996. Presence of antibodies to native $\mathrm{G} 1$ domain of aggrecan core protein in synovial fluids from patients with various joint diseases. Arthritis Rheum. 39:1990-1997.

7. Verheijden, G.F., et al. 1997. Human cartilage glycoprotein-39 as a candidate autoantigen in rheumatoid arthritis. Arthritis Rheum. 40:1115-1125.

8. Zhang, Y., et al. 1998. Induction of arthritis in BALB/c mice by cartilage link protein: involvement of distinct regions recognized by $\mathrm{T}$ and $\mathrm{B}$ lymphocytes. Am. J. Pathol. 153:1283-1291.

9. McKee, P.H. 1996. Pathology of the skin with clinical correlations. MosbyWolfe, Times Mirror International Publishers Ltd. London, United Kingdom. 8.27-8.28.

10. McAdam, L.P., O’Hanlan, M.A., Bluestone, R., and Pearson, C.M. 1976. Relapsing polychondritis: prospective study of 23 patients and a review of the literature. Medicine. 55:193-215.

11. Zeuner, M., et al. 1997. Relapsing polychondritis: clinical and immunogenetic analysis of 62 patients. J. Rheumatol. 24:96-101.

12. Maddison, P.J. 1993. Miscellaneous disorders of bone, cartilage, and synovium. In Oxford textbook of rheumatology. P.J. Maddison, D.A. Isenberg, P. Woo, and D.N. Glass, editors. Oxford University Press. New York, NY $1038-1042$

13. O'Hanlan, M., McAdam, L.P., Bluestone, R., and Pearson, C.M. 1976. The arthropathy of relapsing polychondritis. Arthritis Rheum. 19:191-194.

14. Michet, C.J., Jr., McKenna, C.H., Luthra, H.S., and O'Fallon, W.M. 1986. Relapsing polychondritis. Survival and predictive role of early disease manifestations. Ann. Intern. Med. 104:74-78.

15. Lang, B., et al. 1993. Susceptibility to relapsing polychondritis is associated with HLA-DR4. Arthritis Rheum. 36:660-664.

16. Trentham, D.E., Townes, A.S., and Kang, A.H. 1977. Autoimmunity to type II collagen: an experimental model of arthritis. J. Exp. Med. 146:857-868

17. Cremer, M.A., et al. 1994. Type XI collagen-induced arthritis in the Lewis rat. Characterization of cellular and humoral immune responses to native types XI, V, II collagen and constituent $\alpha$-chains. J. Immunol. 153:824-832

18. Glant, T.T., Mikecz, K., Arzoumanian, A., and Poole, A.R. 1987. Proteoglycan-induced arthritis in Balb/c mice. Arthritis Rheum. 30:201-212

19. Carlsen, S., Hansson, A.-S., Olsson, H., Heinegård, D., and Holmdahl, R 1998. Cartilage oligomeric matrix protein (COMP) induced arthritis in rats. Clin. Exp. Immunol. 114:477-484.

20. Paulsson, M., and Heinegård, D. 1979. Matrix proteins bound to associatively prepared proteoglycans from bovine cartilage. Biochem. J 183:539-545.

21. Agraves, W.S., Deák, F., Sparks, K.J., Kiss, I., and Goetinck, P.F. 1987. Structural features of cartilage matrix protein deduced from cDNA. Proc. Natl. Acad. Sci. USA. 84:464-468.

22. Kiss, I., et al. 1989. Structure of the gene for cartilage matrix protein, a modular protein of extracellular matrix. J. Biol. Chem. 264:8126-8134.

23. Jenkins, R.N., et al. 1990. Structure and chromosomal location of the human gene encoding cartilage matrix protein. J. Biol. Chem. 265:19624-19631.

24. Aszódi, A., et al. 1996. Cloning, sequencing and expression analysis of mouse cartilage matrix protein cDNA. Eur. J. Biochem. 236:970-977.

25. Paulsson, M., and Hauser, N. 1994. Native cartilage matrix protein (CMP). J. Biol. Chem. 269:25747-25753.

26. Beck, K., Gambee, J.E., Bohan, C.A., and Bächinger, H.P. 1996. The C-terminal domain of cartilage matrix protein assembles into triple-stranded $\alpha$-helical coiled-coil structure. J. Mol. Biol. 256:909-923.

27. Winterbottom, N., et al. 1992. Cartilage matrix protein is a component of the collagen fibril of cartilage. Dev. Dyn. 193:266-276.

28. Chen, Q., Johnson, D.M., Haudenschild, D.R., and Goetinck, P.F. 1995. Progression and recapitulation of the chondrocyte differentiation program: cartilage matrix protein is a marker for cartilage maturation. Dev. Dyn. 172:293-306.

29. Paulsson, M., Inerot, S., and Heinegård, D. 1984. Variation in quantity and extractability of the 148-kilodalton cartilage protein with age. Biochem. J. 221:623-630.

30. Paulsson, M., and Heinegård, D. 1982. Radioimmunoassay of the 148kilodalton cartilage protein. Biochem. J. 207:207-213.

31. Saxne, T., and Heinegård, D. 1989. Involvement of nonarticular cartilage as demonstrated by release of a cartilage-specific protein, in rheumatoid arthritis. Arthritis Rheum. 32:1080-1086

32. Okimura, A., et al. 1997. Enhancement of cartilage matrix protein synthesis in arthritic cartilage. Arthritis Rheum. 40:1029-1036.

33. Wagener, R., Kobbe, B., and Paulsson, M. 1997. Primary structure of matrilin-3, a new member of a family of extracellular matrix proteins related to cartilage matrix protein (matrilin-1) and von Willebrand fac- tor. FEBS Lett. 413:129-134.

34. Deák, F., Piecha, D., Bachrati, C., Paulsson, M., and Kiss, I. 1997. Primary structure and expression of matrilin-2, the closest relative of cartilage matrix protein within the von Willebrand factor type A-like module superfamily. J. Biol. Chem. 272:9268-9274.

35. Saxne, T., and Heinegård, D. 1995. Serum concentrations of two cartilage matrix proteins reflecting different aspects of cartilage turnover in relapsing polychondritis. Arthritis Rheum. 38:294-296

36. Paulsson, M., and Heinegård, D. 1981. Purification and structural characterization of a cartilage matrix protein. Biochem. J. 197:367-375.

37. Paulsson, M., and Hauser, N. 1994. Native cartilage matrix protein (CMP). J. Biol. Chem. 269:25747-25753.

38. Smith, B.D., Martin, G.R., Miller, E.J., Dorfman, A., and Swarm, R. 1975. Nature of the collagen synthesized by a transplanted chondrosarcoma. Arch. Biochem. Biophys. 166:181-186.

39. Miller, E.J., and Rhodes, R.K. 1982. Preparation and characterization of the different types of collagen. Methods Enzymol. 82:33-64.

40. Hedbom, E., et al. 1992. Cartilage matrix proteins. An acidic oligomeric protein (COMP) detected only in cartilage. J. Biol. Chem. 267:6132-6136.

41. Brostoff, S.W., and White, T.M. 1986. Treatment of clinical experimental allergic encephalomyelitis in the rat with monoclonal antibodies. $J$. Neuroimmunol. 13:233-240.

42. Brideau, R.J., Carter, P.B., McMaster, W.R., Mason, D.W., and Williams, A.F. 1980. Two subsets of rat T-lymphocytes defined with monoclonal antibodies. Eur. J. Immunol. 10:609-615.

43. Hünig, T., Wallny, H.J., Hartley, J.K., Lawetzky, A., and Tiefenthaler, G. 1989. A monoclonal antibody to a constant determinant of the rat $\mathrm{T}$ cell antigen receptor that induces $T$ cell activation. Differential reactivity with subsets of immature and mature T lymphocytes. J. Exp. Med. 169:73-86.

44. Dallman, M.J., Thomas, M., and Green, J.R. 1984. MRC OX19: a monoclonal antibody that labels rat $\mathrm{T}$ lymphocytes and augments in vitro proliferative responses. Eur. J. Immunol. 14:260-267.

45. McMaster, W.R., and Williams, A.F. 1979. Monoclonal antibodies to Ia antigens from rat thymus. Crossreactions with mouse and human and use in purification of rat Ia glycoproteins. Immunol. Rev. 47:117-135.

46. Hsu, S., Raine, L., and Fanger, H. 1981. Use of avidin-biotin-peroxidase complex $(\mathrm{ABC})$ in immunoperoxidase techniques. J. Histochem. Cytochem. 29:577-580

47. True, L.D. 1990. Methods and techniques. In Atlas of diagnostic immunohistopathology. L.D. True, editor. Gower Medical Publishing. New York, NY. 2.1-2.20.

48. Goldschmidt, T.J., and Holmdahl, R. 1991. Anti-T cell receptor antibody treatment of rats with established autologous collagen-induced arthritis. Suppression of arthritis without reduction of anti-type II collagen autoantibody levels. Eur. J. Immunol. 21:1327-1330.

49. Holmdahl, R., Olsson, T., Moran, T., and Klareskog, L. 1985. In vivo treatment of rats with monoclonal anti-T-cell antibodies. Immunohistochemical and functional analysis in normal rats and in experimental allergic neuritis. Scand. J. Immunol. 22:157-169.

50. Wicker, L.S., Todd, J.A., and Peterson, L.B. 1995. Genetic control of autoimmune diabetes in the NOD mouse. Annu. Rev. Immunol. 13:179-200.

51. Courtenay, J.S., Dallman, M.J., Dayan, A.D., Martin, A., and Mosedal, B. 1980. Immunization against heterologous type II collagen induces arthritis in mice. Nature. 283:666-667.

52. Jansson, L., Olsson, T., Höjeberg, B., and Holmdahl, R. 1991. Chronic experimental autoimmune encephalomyelitis induced by the 89-101 myelin basic protein peptide in B10RIII (H-2r) mice. Eur. J. Immunol. 3:693-699.

53. Yoshino, S., Schlipkoter, E., Kinne, R., Hunig, T., and Emmrich, F. 1990. Suppression and prevention of adjuvant arthritis in rats by a monoclonal antibody to the alpha/beta T cell receptor. Eur. J. Immunol. 20:2805-2808.

54. Boissier, M.C., Chiocchia, G., Ronziere, M.C., Herbage, D., and Fournier, C. 1990. Arthritogenicity of minor cartilage collagens (types IX and XI) in mice. Arthritis Rheum. 33:1-8.

55. Kindblom, L.-G., Dalèn, P., Edmar, G., and Kjellbo, H. 1977. Relapsing polychondritis: a clinical, pathologic-anatomic and histochemical study of 2 cases. Acta. Pathol. Microbiol. Immunol. Scand. [A]. 85:656-664.

56. Chang-Miller, A., et al. 1987. Renal involvement in relapsing polychondritis. Medicine. 66:202-217.

57. Cremer, M.A., Pitcock, J.A., Stuart, J.M., Kang, A., and Townes, A.S. 1981. Auricular chondritis in rats. An experimental model of relapsing polychondritis induced with type II collagen. J. Exp. Med. 154:535-540.

58. McCune, W.J., Schiller, A.L., Dynesius-Trentham, R.A., and Trentham, D.E. 1982. Type II collagen-induced auricular chondritis. Arthritis Rheum. 25:266-273

59. Bradley, D.S., Das, P., Griffiths, M.M., Luthra, H.S., and Chella, C.S. 1998. HLA-DQ6/8 double transgenic mice develop auricular chondritis following type II collagen immunization: a model for human relapsing polychondritis. J. Immunol. 161:5046-5053.

60. Prieur, D.J., Young, D.M., and Counts, D.F. 1984. Auricular chondritis in fawn-hooded rats. A spontaneous disorder resembling that induced by immunization with type II collagen. Am. J. Pathol. 116:69-76.

61. Vingsbo, C., et al. 1996. Pristane induced arthritis in rats: a new model 
for rheumatoid arthritis with a chronic disease course influenced by both major histocompatibility complex and non-major histocompatibility complex genes. Am. J. Pathol. 149:1675-1683.

62. Vingsbo, C., Jonsson, R., and Holmdahl, R. 1995. Avridine induced arthritis in rats: a $\mathrm{T}$ cell-dependent chronic disease influenced both by MHC and non-MHC genes. Clin. Exp. Immunol. 99:359-363.

63. Holmdahl, R., Goldschmidt, T.J., Kleinau, S., Kvick, C., and Jonsson, R 1992. Arthritis induced in rats with adjuvant oil is a genetically restricted, alpha beta T-cell dependent autoimmune disease. Immunology. 76:197-202.

64. Stuart, J.M., Cremer, M.A., Townes, A.S., and Kang, A.H. 1982. Type II collagen induced arthritis in rats. Passive transfer with serum and evidence that IgG anticollagen antibodies can cause arthritis. J. Exp. Med. 155:1-16.

65. Terato, K., et al. 1990. Specificity of antibodies to type II collagen in rheumatoid arthritis. Arthritis Rheum. 33:1493-1500.

66. Adu, D., Luqmani, R.A., and Bacon, P.A. 1993. Polyarteritis, Wegener's granulomatosis, and Churg-Strauss syndrome. In Oxford textbook of rheumatology. P.J. Maddison, D.A. Isenberg, P. Woo, and D.N. Glass, editors. Oxford University Press. New York, NY. 846-859.

67. Lanham, J.G., Elkon, K.B., Pusey, C.D., and Hughes, G.R. 1984. Systemic vasculitis with asthma and eosinophilia: a clinical approach to the Churg-Strauss syndrome. Medicine. 63:65-81.

68. Geterud, A. 1991. Rheumatoid arthritis in the larynx. Scand. J. Rheumatol. 3:215.

69. McGeehan, D.F., Crinnion, J.N., and Strachan, D.R. 1989. Life-threatening stridor presenting in a patient with rheumatoid involvement of the larynx. Arch. Emerg. Med. 4:274-276. 